Synthesis, part of a Special Feature on Pathways to Resilient Salmon Ecosystems

\title{
Evolutionary History, Habitat Disturbance Regimes, and Anthropogenic Changes: What Do These Mean for Resilience of Pacific Salmon Populations?
}

\author{
$\underline{\text { Robin S. Waples }}^{1} \underline{\text { Tim Beechie }}^{2}$, and $\underline{\text { George R. Pess }}^{2}$
}

\begin{abstract}
Because resilience of a biological system is a product of its evolutionary history, the historical template that describes the relationships between species and their dynamic habitats is an important point of reference. Habitats used by Pacific salmon have been quite variable throughout their evolutionary history, and these habitats can be characterized by four key attributes of disturbance regimes: frequency, magnitude, duration, and predictability. Over the past two centuries, major anthropogenic changes to salmon ecosystems have dramatically altered disturbance regimes that the species experience. To the extent that these disturbance regimes assume characteristics outside the range of the historical template, resilience of salmon populations might be compromised. We discuss anthropogenic changes that are particularly likely to compromise resilience of Pacific salmon and management actions that could help bring the current patterns of disturbance regimes more in line with the historical template.
\end{abstract}

Key Words: climate change; duration; frequency; historical template; magnitude; Pacific Northwest; Oncorhynchus; Pacific salmon; predictability.

\section{INTRODUCTION}

The concept of resilience means different things in different contexts. In the field of communications technology, resilience is the ability of a network to keep functioning and provide services in spite of disturbances to normal operations. In this context, resilience is more or less synonymous with robustness. To physicists, resilience takes a meaning more like elasticity and describes the speed or fidelity with which a material returns to its original state after it has been deformed. Ecologists have often used resilience to refer to a similar phenomenon: the ability of a biological system to return to equilibrium after a perturbation. However, Holling (1973) argued that stability is a better term for this quality, and that the concept of ecological resilience more properly refers to the ability of a system to absorb change and still maintain its basic system of relationships without flipping into a different configuration. In this view, resilient biological systems might be inherently unstable but nevertheless persistent. Holling (1973:18) also noted that "the balance between resilience and stability is clearly a product of the evolutionary history of these systems in the face of the range of random fluctuations they have experienced." This quote emphasizes the important point that ecological resilience incorporates both forward-and backward-looking components: we typically think of resilience as a property that describes future behavior of a biological system, but that behavior is the consequence of attributes of the system that have been forged over time in the crucible of past evolutionary events.

In this paper, we consider how the evolutionary history of Pacific salmon (Oncorhynchus spp.) and the dynamic ecosystems they inhabit have conferred considerable resilience on this important natural resource. We include in the term "Pacific salmon" not only the five species traditionally recognized from North America (pink salmon, O. gorbuscha; chum salmon, O. keta; coho salmon, O. kisutch; sockeye salmon, $O$. nerka; Chinook salmon, $O$. tshawytscha) but also steelhead, the anadromous form of rainbow trout, $O$. mykiss. Pacific salmon have evolved in an environment that is both 
physically and climatically dynamic, with the major extant lineages developing during the last ice age, which occurred $\sim 400,000 \mathrm{yr}$ to $16,000 \mathrm{yr}$ ago, and current metapopulation structure developing during a period of rapid landscape evolution $\sim 16,000 \mathrm{yr}$ ago to present (Waples et al. 2008). Over the past two centuries, however, rapid climate change and major anthropogenic modifications to salmon ecosystems have dramatically altered disturbance regimes that salmon experience. To the extent that these disturbance regimes assume characteristics outside the range of the historical template the species evolved under, resilience of salmon populations might be compromised. We discuss anthropogenic changes that are particularly likely to compromise resilience of Pacific salmon and management actions that could help bring the current patterns of disturbance regimes more in line with the historical template. Resilience can be assessed at several spatial and temporal scales. For example, a variety of factors can affect salmon viability and make local spawning populations either more or less resilient to environmental fluctuations or anthropogenic changes (McElhany et al. 2000). And the degree to which the responses of different populations to perturbations are uncorrelated can confer resilience on larger geographic scales (Good et al. 2008). Furthermore, this latter type of resilience has a deeper temporal dimension that can extend well beyond the expected persistence time of any individual population.

\section{THE HISTORICAL TEMPLATE}

Waples et al. (2008) recently reviewed major features in the evolution of Pacific salmon and their habitats. Key points that emerged from this joint analysis include the following:

1. Speciation within Oncorhynchus was complete by the late Miocene, leaving several million years for evolution within each of the salmon species. However, none of the extant, intraspecific lineages are anywhere near that old. Several lineages probably date from the Pleistocene.

2. A great deal of diversity has developed during the Holocene, through a combination of recolonization of deglaciated habitats, e.g., Puget Sound and most of British Columbia, and in situ evolution.
3. Major, but rare, habitat upheavals such as late-Pleistocene megafloods and volcanism have had long-lasting impacts on salmon evolution.

4. In many areas, postglacial rebound and associated habitat changes stabilized by about 5000 yr ago, leaving ample time for contemporary salmon populations to have reached a dynamic equilibrium between genetic drift, migration, and local adaptation.

5. The spatial and temporal scales on which disturbance regimes operate have provided the framework within which the processes shaping Pacific salmon evolution have operated.

6. Recent anthropogenic changes have altered characteristics of disturbance regimes and created novel evolutionary pressures for Pacific salmon.

What features of the historical template are important for resilience of Pacific salmon? Here, we consider both the physical and biological aspects of this problem.

\section{Dynamic attributes of salmon habitats}

Salmon habitats are dynamic in many ways, including annual movement because of channel migration, shifting locations of wood accumulations that form pools, and changes in structure and function of riparian forests as floodplain surfaces erode and form anew elsewhere; in addition, shortterm perturbations of habitats occur during floods or low flow periods. These processes create a dynamic mosaic of habitats to which salmon are adapted, and disturbance regimes are fundamental in shaping those environments (Stanford et al. 1996, Independent Scientific Group 1999, Bisson et al. in press). Disturbance regimes can be characterized by four main attributes (Lytle and Poff 2004): (1) how often the event occurs (frequency); (2) spatial extent and severity (magnitude); (3) the length of the disturbance; press and pulse (duration); and (4) novel to routine (predictability). These attributes can be applied to each of the five main drivers of habitat condition and use by salmon: sediment supply regime, hydrologic regime, thermal regime, riparian vegetation, and connectivity (Table 1), as well as to river channels and habitats themselves. 
However, the characterization of each disturbance regime is scale dependent, because a disturbance at a small scale, such as a landslide temporarily killing off a small spawning population in a single tributary, is simply part of the normal pattern at a larger scale. For example, landslides occur every year at a few locations within a large river basin.

Because the attributes of disturbance regimes are intertwined, it is difficult to separate them cleanly and assess how salmon are resilient to the various components. Moreover, each of the five main drivers has multiple disturbance attributes, as well as multiple directions of human impact on the regime. For example, hydrologic regime encompasses both peak and low flows, each of which influences salmon population performance, and human impacts can either reduce or exaggerate both attributes. Dam operations might dampen peak flows and increase low flows, whereas urbanization or climate change might increase peak flows and decrease low flows. Hence, it is difficult to summarize all the characteristics of natural disturbance regimes in a simple way, and to assess how human activities alter each aspect of disturbance regime. Here we describe some key aspects of disturbance regimes that salmon experience to set the stage for assessing their responses to dynamic environments.

Hydrologic and sediment supply regimes that occurred prior to European settlement were typified on the one hand by high-magnitude, low-frequency events such as floods and landslides, and on the other hand by infrequent periods of low flow or sediment supply (Reeves et al. 1995). Floods occur annually throughout the Pacific Northwest, and most extreme events tend to occur either during fall and winter rain storms combined with snowmelt (Sumioka et al. 1998), or during localized stormrelated flood events in spring and summer. Low flows for most salmon populations occur in late summer and early fall, and in some regions long reaches of river are dry for weeks to months during that period. High-intensity rainfall events are the primary drivers of erosion, both in coastal areas where landslides dominate and in the interior where surface erosion dominates (Beechie et al. 2003). Erosion events can reduce salmon survival in a local area for up to several years, but most are too small to significantly alter channel morphology and habitat structure. By contrast, long periods of low erosion intensity can lead to sediment-poor stream conditions and lack of spawning and rearing habitat. Although this is not a common occurrence within the range of Pacific salmon, such episodes of low sediment supply can persist for decades to centuries until fires and storms conspire to increase sediment delivery rates (Benda and Dunne 1997).

Riparian vegetation varies from grasses and willow or brush species in semiarid regions to dense stands of large conifers in coastal rain forests. Disturbance regimes are driven by two main processes: fire in relatively small streams (Beechie et al. 2000) and channel migration and bank erosion in larger rivers (Beechie et al. 2006a, Laterell et al. 2007). Hence, wood recruitment regimes vary from minimal quantities in semiarid regions (excepting beaver use of small wood to build beaver dams; Pollock et al. 2007) to large and consistent annual inputs in which floodplains continuously erode patches each year and incorporate trees into the channel (Latterell et al. 2007). Wood recruitment is most episodic in small streams, in which bank erosion is minimal and wood is delivered in pulses as a result of fires.

Although this paper will focus on freshwater habitats, it is worth noting that ecological and evolutionary processes in salmon populations are also shaped by natural disturbance processes in estuaries and near-shore marine areas. These habitats are also dynamic on both short and long time scales as a result of geological processes (e.g., subduction-zone earthquakes), and oceanographic processes (coastal upwelling, ENSO oscillations, etc.). In contrast to discrete ecosystems such as lakes, therefore, the ecosystems that Pacific salmon depend upon are open systems with fluid boundaries (Bottom et al. 2009), a reality that presents special challenges for assessing and managing resilience.

\section{Biological attributes of salmon populations}

Collectively, these patterns of dynamic change to their habitats represent the evolutionary milieu of Pacific salmon. In this section, we outline some of the biological attributes of salmon populations that contribute to their resilience in the face of these patterns of change. We refer the reader to Groot and Margolis (1991), Hendry and Stearns (2004), and Quinn (2005) for detailed treatments of salmon biology, and to Healey (2009) for additional discussion of how these factors affect resilience. 
Table 1. Descriptions of typical natural and altered disturbance regimes.

\section{Connectivity within natural range}

Magnitude

Frequency

Duration

Predictability

\section{Sediment supply}

Magnitude

Frequency

Duration

Predictability

\section{Hydrologic regime}

Magnitude

Frequency

Duration

Predictability

\section{Thermal regime}

Magnitude
Landslide dams may block migration to very small, e. g., a single tributary or large areas, e.g., most of the Fraser River

Migration blockages are rare, < once every thousand years in most locations

Most landslide dams are temporary, lasting hours to days.

Locations are not very predictable.

Magnitude of sediment supply varies spatially and temporally, driven by precipitation intensity, duration, and extent.

Sediment supply is episodic. Some sediment enters a river system each year, but location, amount, timing, type, size, etc. vary from year to year.

Duration of sediment supply generally mirrors storm durations.

Stochastic

Spatial extent of storms and associated floods can be as small as a single watershed, or as large as an entire region, e.g., the 1964 storm, in which record floods occurred from northern California to southern Washington.

Large floods or extreme low flows typically occur several times in a given year.

Ranges between hours, days, and weeks

Highly predictable on an annual scale, e.g., whether they will occur; less predictable at the monthly, weekly, or daily scale

Temperature extremes rarely exceed tolerances of most salmon populations.
Sediment supply generally increases due to land uses such as forestry, grazing, or cultivation.

Land uses such as forestry tend to increase the frequency of sediment inputs to rivers.

Little change from land use

Stochastic, but more frequent

Typically reduced due to dams absorbing the peak flows

Peak and low flows are typically reduced at the seasonal and annual time scale, whereas diurnal range may be increased at the daily time scale.

Rivers regulated by dams typically increase the duration of peak flows.

Greater predictability due to rivers being regulated by dams

Temperature extremes commonly exceed tolerances of many salmon populations. 
Frequency

Duration

Predictability

\section{Riparian vegetation}

Magnitude

Frequency

Duration

Predictability

\section{Nutrient regime}

Magnitude

Frequency

Duration

Predictability
No exceedence in most years at most locations

Days to weeks

Predictable
Several times a year in most locations

Days to weeks

Predictable

Small streams: Fires periodically kill riparian forest patches.

Large rivers: River erosion periodically removes patches of floodplain forest.

Small streams: fire reset vegetation at return intervals of 50-400 yr

Large rivers: erosion reset forests at intervals of 1 to $\sim 100$ s of $\mathrm{yr}$

Forests begin regeneration soon after disturbance.

Fire: unpredictable

Erosion: predictable

Millions of salmon returning

Annual

Salmon returning in most months of the year

Predictable
Fires and erosion rarely kill riparian forest patches, but logging and land conversion kill a greater expanse of riparian forests.

Logging: return interval of $<50 \mathrm{yr}$ in most cases, riparian protections recently enacted in some areas Land conversion: generally kills forests once

Logging: forests begin regeneration soon after disturbance.

Land conversion: often no regeneration, i.e., duration of decades to centuries

Predictable

Few to no salmon returning in many areas

Annual

Salmon returning in most months, but shorter spawning runs for many populations

Predictable

\section{Life history diversity}

Pacific salmon exhibit a rich variety of life history traits, both within and among populations. Some of the traits that are most important for resilience are summarized in Table 2. When juvenile salmon migrate from fresh water to the sea they are known as smolts, and this can occur anywhere from a few days to two or more years after they emerge from the gravel in which the female salmon deposits her eggs. In some species, a fraction of individuals returns to fresh water to spawn the same year they emigrate as smolts, but most spend one or more winters at sea before initiating their spawning migration. Together, these two traits define the age structure of a salmon population. Two species, $O$. nerka and $O$. mykiss, have forms that spend their entire life cycles in fresh water without ever migrating to sea. This trait can be characteristic of an entire population, or it can be a polymorphism within a single population. Finally, all 'true' Pacific salmon die after spawning, but resident forms of $O$. mykiss are iteroparous, and some fraction of anadromous steelhead also spawn more than once.

All else being equal, populations that can express any of several juvenile and marine life history strategies will be less strongly affected by extreme environmental events, good or bad, that affect a single year class. Likewise, if a population complex 
Table 2. Occurrence of major life history traits in native Pacific salmon populations from North America. Symbols represent proportion of populations that predominantly express the indicated trait: +++ majority; ++ approximately half; + minority; - trait is absent in the species; * a minority of individuals in some populations express the trait. Modified from Waples et al. (2001).

\begin{tabular}{lcccccccccc}
\hline \hline Species & \multicolumn{3}{c}{ Age at smolting } & \multicolumn{3}{c}{ Winters at sea } & \multicolumn{2}{c}{ Anadromous } & \multicolumn{2}{c}{ Spawning } \\
\hline \multirow{2}{*}{ Pink } & $<1$ & 1 & $>1$ & $<1$ & 1 & $>1$ & Yes & No & Semelparous & Iteroparous \\
Chum & All & - & - & - & All & - & All & - & All & - \\
Sll & - & - & - & - & All & All & - & All & - \\
Cockeye & + & + & +++ & - & + & +++ & +++ & + & All & - \\
Chinook & $*$ & +++ & $+^{\mathrm{a}}$ & $* \mathrm{~b}$ & All & $*$ & All & - & All & - \\
Steelhead & - & $++^{\mathrm{a}}$ & $*$ & $* \mathrm{~b}$ & + & +++ & All & $*$ & All & - \\
\hline
\end{tabular}

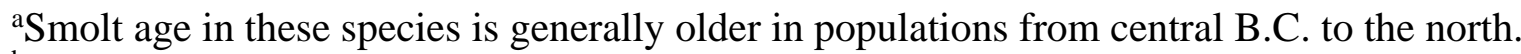

bonly males express this trait.

'In most pure steelhead populations, the fraction of individuals that spawns more than once is small.

contains populations that have different suites of life history traits, overall abundance can be buffered against environmental fluctuations that occur on a variety of temporal scales (Hilborn et al. 2003, Koski et al. 2009). Moreover, populations with diverse life histories can take advantage of habitats that cannot support a population through all its freshwater life stages. For example, coho "nomads," (fry outmigrants) rear in estuaries for their first summer, then migrate into tributaries to overwinter. This life history strategy allows coho smolts to be produced from streams that lack suitable spawning habitat, and conservation of both estuarine and overwinter habitats is crucial to maintaining high smolt production from streams that otherwise could not support coho salmon (Koski et al. 2009).

\section{Homing and straying}

Pacific salmon are justifiably renowned for their ability to return to spawn at the precise location at which they were hatched. However, homing is not perfect, which leads to a generally low level of natural straying among populations. The interplay between homing and straying helps to shape the adaptive landscape for Pacific salmon. Homing fidelity is strong enough that local populations can become adapted to their particular environments (Taylor 1991). However, except for populations that become isolated above natural barriers, e.g., waterfalls created by glacial rebound, most salmon populations are part of larger metapopulations that are connected by migration. This ensures that local populations do not become too small and isolated and that each contains an appreciable fraction of the genetic variation contained by the species. Furthermore, straying provides a source of colonists that can promote recovery after major disturbances and local population declines (Leider 1989). This behavior helps salmon to persist in highly dynamic environments and to rapidly expand their range when conditions permit (Milner and Bailey 1989).

Sockeye salmon exhibit both extremes on the continuum of homing vs. straying. Most sockeye populations are associated with lakes, which promotes isolation, a stronger degree of population genetic differentiation than is found in other Pacific 
salmon, and highly specialized adaptations (Burgner 1991, Wood 1995). Although lake-type sockeye populations can be enormously productive (Foerster 1968), these specialized habitats are vulnerable to environmental changes. Conversely, river-type sockeye are more generalized in their habitat requirements but also relatively rare, or perhaps only poorly documented, and only weakly differentiated based on neutral genetic markers (Wood 1995, Gustafson and Winans 1999, Wood et al. 2008). Although highly specialized, most laketype sockeye populations might be evolutionary dead ends, and it might be the river-type populations, which are more likely to produce successful colonists, that confer more resilience on the species as a whole (Wood 1995, 2007, Wood et al. 2008; but see Pavey et al. 2007).

\section{Phenotypic plasticity}

Phenotypic plasticity is the ability of the same genotype to produce a different phenotype under different environmental conditions. Expression of most of the life history traits in Table 2, as well as many others, can be strongly affected by factors such as water temperature, food availability, growth rate, etc. Plasticity can be expressed at the level of the individual, for example, growth rate of individual fish typically varies with temperature, and integrated up to the population level. At the individual level, plasticity allows a salmon to make behavioral or physiological adjustments that allow it to thrive through a range of environmental conditions. The relationship between the expression of particular phenotypes and their associated environments is known as an individual's norm of reaction (Hutchings 2004). If reaction norms differ among individuals within a population, the capability of the population for a plastic response to environmental change is further enhanced, without the requirement for genetic change.

\section{Rapid evolution}

Each species of Pacific salmon comprises a number of evolutionarily significant units (ESUs; Waples 1991, 1995), which are groups of populations that share life history/genetic/ecological traits to a substantially greater degree than do populations from different ESUs. Salmon ESUs are meant to represent units that follow largely independent evolutionary trajectories over hundreds or thousands of years. However, evidence is accumulating to show that Pacific salmon are also capable of relatively rapid evolution, on human time scales. It seems, therefore, that within a century or so, perhaps less in some cases, genetic and phenotypic differences can be produced that are comparable to those found between Pacific salmon populations from within the same ESU (Quinn et al. 2001, Waples et al. 2004).

\section{SYNTHESIS}

Joint consideration of temporal and spatial scales of physical and biological changes in salmon populations and their habitats indicates that the historical template was really a shifting mosaic, with constant changes overlaid on some more robust underlying processes. On a very local scale (a single deme, or group of spawners within a population) the chances are small of a major habitat disturbance occurring during any particular year, but over long periods of time the probability of a severe event approaches unity. High productivity and variable age at maturity can help buffer demes against severe disturbances, but periodic extinction of such units is part of the evolutionary history of salmon. As the geographic scale under consideration increases to populations, metapopulations, or larger conservation units or ESUs, it becomes more likely that a severe disturbance will occur somewhere during any given time period, but the effects on the overall metapopulation or conservation unit will be modulated by normal conditions elsewhere. salmon in nearby tributaries often will survive local disturbances and can provide strays to repopulate extirpated demes and populations. Resilience of the species as a whole is thus enhanced by the existence of many demographically independent populations replicated across the landscape.

Together, these physical processes and the biological attributes of salmon populations promote local adaptations, while at the same time making it unlikely that any particular locally adapted population will persist indefinitely. Therefore, if one were able to travel back in time and take a series of snapshots of habitat features and associated salmon biology, one might expect to find the following: (1) at any point in time, a large fraction of salmon populations will have acquired genetically based adaptations to local conditions; but (2) fine-scale patterns of adaptation would change over time. That is, each time period might be characterized by a general pattern of locally adapted populations, but specific habitat features 
would have evolved between time periods and as a consequence the biological attributes of individual populations would evolve as well. Thus, although specific local adaptations between salmon and their habitats are not necessarily stable over long time periods, the general pattern of locally adapted populations spread across a dynamic landscape is much more robust, and it is this broader pattern that is one of the major factors that confers resilience to the system as a whole.

Not all species are affected in the same way or to the same extent by these processes. A useful way to evaluate the effects of a species' life history on resilience is by using the four criteria that characterize viable salmonid populations (VSP; McElhany et al. 2000): abundance, productivity, spatial structure, and diversity (genetics, life history, ecology). All four criteria are evaluated at the level of individual populations, and the last two criteria are also used to help guide the process of integrating the population data into an overall assessment of viability of larger conservation units and ESUs. At one extreme of the life history diversity of Pacific salmon, Pink salmon show little variation either within or between populations (Table 2). Fixed age at maturity provides no opportunity for different cohorts to fill in for catastrophic losses. In this species, resilience primarily is a product of high abundance and productivity and relatively high straying rates, which create a metapopulation structure that serves to spread the risk across multiple streams. This species migrates to sea shortly after emergence and hence avoids many problems associated with rearing in dynamic freshwater habitats. For Pink salmon, therefore, diversity is limited and is not as important a contributor to resilience as are the other criteria such as abundance and productivity.

At the other end of the spectrum, Chinook salmon and steelhead support a rich diversity of life history types, both within and among populations. These species penetrate into higher elevation tributaries, in which opportunities for isolation and local adaptation are greater, and as juveniles they spend longer periods in fresh water than do Pink or chum salmon. Chinook salmon can spend up to $5 \mathrm{yr}$ at sea and steelhead can spawn more than once; this wide variation in age at maturity provides ample opportunity for other year classes to compensate for a decimated cohort. Abundance of individual populations typically is lower than for Pink salmon, but the rich diversity of life history types makes it likely that at least some will be successful under any given set of environmental conditions. For Chinook and steelhead, therefore, spatial structure and diversity play particularly important roles in promoting resilience.

$O$. mykiss and $O$. nerka also have resident as well as anadromous forms, which provides an additional component of diversity and an additional layer of flexibility to respond to challenging environmental conditions. Downstream migrants from resident populations can accelerate the range and rate of colonization after disturbances events, because of positive spawning interactions with upstreammoving anadromous populations. On the Olympic Peninsula in Washington State, interactions between the two forms of O. mykiss, female steelhead and resident male rainbow trout) occur primarily at the end of the spawning season (McMillan et al. 2007). In controlled experiments, female steelhead $\times$ resident rainbow crosses can produce over $25 \%$ of the offspring that migrate to sea as smolts (Ruzycki et al. 2003, unpublished report). Other species that have resident life forms, such as $O$. nerka (kokanee), have shown contributions to anadromous life forms, but at a much smaller percentage $(<1 \%)$ of the total offspring (Foerster 1947, Kaeriyama et al. 1992).

Resident populations by themselves can also increase the rate of recolonization after disturbance events even without interaction with anadromous life forms. For example, brook trout populations upstream of disturbed areas can colonize and establish spawning populations in recently disturbed downstream reaches within several years after a migration barrier caused by a major landslide (Roghair and Dolloff 2005). Purely resident life forms of $O$. mykiss can also colonize downstream areas, and have been shown to produce a small portion of the overall total of out-migrating smolts in some areas (Ruzycki et al. 2003, unpublished report). Similarly, coastal bull trout (Salvelinus confluentus) have an anadromous life form on the Olympic Peninsula, and are known to move between freshwater and marine environments throughout their lifetime (Brenkman and Corbett 2005).

\section{Anthropogenic changes: altered disturbance regimes}

If Holling (1973) is correct that resilience of biological systems is shaped by their evolutionary 
history and the range of random fluctuations they have experienced, then factors that alter this historical template can have profound effects on resilience. Habitats available to salmon have been reduced by diking and draining of marshlands (Beechie et al. 2001, Collins and Montgomery 2001), migration barriers (Sheer and Steel 2006), and flooding by reservoirs (Dauble and Geist 2000), and these changes have obvious consequences for population viability. However, these factors have been covered elsewhere (McElhany et al. 2000, Bottom et al. 2005, McClure et al. 2008). In this section, we focus on how anthropogenic changes to salmon habitats have altered disturbance regimes in ways that affect resilience. We discuss these changes in the context of the four attributes of disturbance regimes identified above: frequency, magnitude, duration, and predictability.

Anthropogenic activities can either reduce or increase the frequency of disturbances. Dams and water storage in reservoirs typically suppress peak flows and augment low flows, thereby dampening flow variation throughout the year. Large floods create new channels and recruit wood from the floodplain, and elimination, or large reductions in frequency, of this key habitat-forming process reduces the complexity of salmon rearing habitats, with attendant effects on the VSP parameters spatial structure and diversity. Bank protection to stop river movements across floodplains also reduces habitat, and consequently life history diversity because new habitats are not allowed to form; thus, existing habitats gradually develop into floodplains. Furthermore, inhibiting channel movement reduces wood recruitment from floodplains, and also shifts floodplain forest composition to older age classes over the long term. Each of these impacts reduces habitat variation in the river landscape, which narrows the range of life history options available to salmon. That is, reduced habitat diversity leads to reduced life history diversity, primarily because habitat types necessary for the expression of certain life history variants are lost (e.g., Beechie et al. $2006 b$ ). Such reductions in life history diversity then lead to reduced resilience of salmon populations.

Conversely, many land-use activities increase the frequency of floods and landslides or alter the relationship between frequency and magnitude of these events (Ward and Stanford 1995, Collins et al. 2002, Poff et al. 2007). Increased flood magnitudes result from timber harvest, construction of logging road networks, conversion of forests to agricultural land uses, or urbanization (Benda and
Dunne 1997, Beschta et al. 2000). To take one typical example, the magnitude of floods that used to occur every 10-20 yr in a Puget Sound River now occurs on an almost annual basis (Waples et al. 2008). Large floods typically cause high mortality in salmon by scouring eggs from redds, i.e., salmon nests, suffocating developing embryos by sediment and low oxygen levels, and displacing recently emerged fry downstream. Under the historical template, salmon were adapted to deal with events like this once every several salmon generations. Variable age at maturity provides an effective resilience mechanism for this type of disturbance; if events are not too frequent, other year classes can compensate for high mortality in certain cohorts. However, when floods of this magnitude occur multiple times within each salmon generation, they can exceed the capability of salmon to compensate through evolution or phenotypic plasticity. Indeed, Greene et al. (2005) found that occurrence of more frequent floods was associated with declines in productivity in a Puget Sound Chinook salmon population.

The magnitude of many anthropogenic changes to salmon habitats falls well within the range of the historical template, but the consequences are nevertheless novel because they are replicated widely across the landscape. Culverts are a good example: an individual culvert can mimic a natural feature in salmon-bearing streams by serving as a small local barrier or impediment to upstream migration. However, culverts are pervasive in human-altered landscapes, and their cumulative effects can be substantial in reducing population size and connectivity (Pess et al. 2005a). Similarly, although the magnitude of any given humaninduced landslide typically is comparable to what would occur under natural conditions, intensive forestry and agricultural practices can increase sediment supply to many reaches simultaneously. This elevates salmon mortality in adjacent reaches and reduces the number of colonists available to repopulate depleted streams. This process of replication of the same type of disturbance widely across broad geographic areas departs from the historical template and can reduce resilience and increase extinction risk because the spatial correlation of catastrophic events is increased (Good et al. 2008). Furthermore, replication of similar effects over broad geographic areas selectively affects certain life history types, with potentially long-term effects on resilience (McClure et al. 2008). 
Finally, anthropogenic influences have strongly affected the duration and predictability of disturbance regimes. In particular, many human changes are essentially permanent, at least on ecological time frames, and inhibit or prevent natural processes of habitat restoration that occurred under the historical template. For example, natural landslides are common even in pristine habitat, but the vast majority are passable after a few hours or days. Even major landslides that have occurred in the mainstem Columbia (O'Connor 2004) and Fraser (Evenden 2004) Rivers are naturally breached by the river within a few days, although they can impede migration of anadromous fish for decades or more. In contrast, man-made dams can block migration indefinitely, with profound effects on all the VSP parameters. Similarly, diking and draining of floodplain habitats and isolating them from rivers by levees (Collins and Montgomery 2001, Pess et al. 2005b) represents an essentially permanent disruption of connectivity between habitats compared to natural shifts in connectivity that result from long-term river migrations and periodic isolation of channels on floodplains.

The effects of duration and predictability of impediments to migration are perhaps most strongly seen in species such as $O$. mykiss and $O$. nerka, which have numerous resident as well as anadromous populations. Resident forms of $O$. mykiss are most common where migration is very arduous such as in the interior Columbia River Basin, where anadromous salmonids spawn up to $1500 \mathrm{~km}$ from the sea, or the ability to migrate is unpredictable. For example, some streams in central and southern California do not achieve high enough flows to breach the sand berm at the mouth of the river every year. Impassable dams convert a situation characterized by unpredictable migration into one in which migration is predictably impossible. Even if dams with provision for fish passage only increase the demographic cost of migration, this can tip the scales toward resident forms (Thériault et al. 2008). If resilience is the ability of a system to resist flipping to another state, this implies that a resilient system would be one that conserved the ability to express either anadromy or nonanadromy. However, in the face of strong directional selection against migratory individuals, the genetic architecture capable of expressing anadromy can be lost or compromised in the population, leaving the system stuck in one configuration (resident form only). Although parallel evolution of resident forms from anadromous ones has occurred repeatedly in several Pacific and Atlantic salmonids (Hendry and Stearns 2004, Waples et al. 2004), little empirical evidence exists that resident populations can produce viable anadromous populations, at least on human time frames. A notable exception is the Santa Cruz River in Argentina, in which resident rainbow trout introduced from North America have produced a strong phenotypic component of anadromy (RivaRossi et al. 2007). In this case, novel environmental conditions and lack of competitors and/or predators likely contributed to the shift in life history expression.

\section{Management options: approximating the historical template}

What can managers, and society in general, do to promote resilience of salmon populations? Thinking about long-term resilience requires an evolutionary perspective. The diverse array of salmon populations and life history strategies that exist today are the product of the long evolutionary history of these species in dynamic habitats. However, merely preserving existing types is not sufficient to provide for long-term sustainability. It is at least as important to conserve evolutionary processes such as patterns of dispersal and connectivity, natural selection, sexual selection, and dynamic interactions with physical and biotic features of the habitat (Moritz 2002). Such processes are difficult to manage directly, and in spite of best intentions, we still know far too little to do this effectively except in rare cases. Therefore, the best general strategy for those interested in conserving evolutionary processes is that articulated by W. P. Kinsella (1982): If you build it, they will come. That is, if we can conserve functioning natural ecosystems, then natural evolutionary processes will develop as a byproduct. This general theme has been expressed a number of times in the past decade by those thinking about ways to promote long-term viability of salmon populations in human-dominated landscapes (Independent Scientific Group 1999, Bottom et al. 2005, Lackey et al. 2006, Williams 2006).

Much has been written about conservation and restoration of salmon ecosystems; here, we focus on actions that can help shape key features of habitat disturbance regimes. Biologists increasingly recognize that these disturbance regimes are a critical feature of salmon landscapes, and that 
humans have altered disturbance regimes to the point that our rivers are far less suitable for salmon than they were historically (Williams 2006). The scientific community has also moved rapidly toward efforts to restore key features of disturbance regimes, including hydrologic and sediment supply regimes, floodplain dynamics, and connectivity among diverse habitats (e.g., Reeves et al. 1995, Pess et al. 2005a, Beechie et al. 2006a, Poff et al. 2007, Bisson et al. in press). These efforts have in common the idea that conservation of natural processes is crucial to the resilience of both habitats and species. We view conservation actions that help approximate historical disturbance regimes as one of three types: (1) actions that release constraints on processes that sustain habitat diversity, (2) actions that attenuate anthropogenically exaggerated disturbance regimes and reduce the frequency of high mortality events, or (3) actions that restore migration pathways to historical habitats to increase the diversity of habitats available to salmon. Figure 1 illustrates how each of these approaches might be applied in practice to strengthen resilience of habitats and salmon populations to climate change.

A key aspect of the first approach (Fig. 1A) is our understanding that landscape and river dynamics form and sustain the diverse habitats in which salmon and other aquatics organisms have evolved (Beechie and Bolton 1999). Specific mechanisms include critical disturbances such as channel forming floods, delivery of sediment and large wood debris to channels, or lateral channel migration across floodplains. Each of these processes forms habitat in the natural environment: channel-forming floods create pools and wood accumulations, sediment supplied to river channels becomes spawning gravel, and lateral migration creates a diverse array of habitat types across a floodplain ecosystem. Although we have altered these regimes to the point that they no longer sustain key habitat features of rivers, we now face the challenge of devising actions that can restore these habitatforming processes and recreate the habitats necessary for salmon to persist. Examples of recent approaches to process-based restoration include the concept of restoring environmental flows (Richter et al. 2006), mimicking natural forest disturbance processes so that sediment supply regimes are also relatively natural (Reeves et al. 1995), and removing or setting back levees to allow natural river dynamics and formation of diverse aquatic habitats. Each of these techniques restores disturbance regimes to more natural rates and magnitudes so that habitats are formed and maintained in sufficient amounts and diversity to support salmon.

The second class of restoration actions, i.e., those that reduce the frequency of artificially high mortality events, address land and water uses that increase mortality of salmon at key life stages (Fig. 1B). Two key examples of these types of impacts are increasing flood flows through land uses and thereby increasing incubation mortality (Waples et al. 2008), and decreasing summer rearing flows via water withdrawals and thereby increasing summer rearing mortality. In both cases, flow magnitudes begin to fall outside the range of natural variation observed in the recent past, and the frequency of extreme events is increased to the point that high mortality occurs more than once per generation. Although salmon are generally equipped with life histories that allow them to persist in disturbanceprone environments, such increases can exceed their tolerances. Therefore, restoration actions, such as minimizing water withdrawals when possible, seek to reduce land-use effects on frequency and magnitude of high-mortality events.

Finally, salmon historically had access to a wide range of habitats, but current access is much reduced (Pess et al. 2005a,b, Sheer and Steel 2006, McClure et al. 2008). Migration barriers in the form of dams and culverts impeded access to many historical habitats that were necessary for sustaining particular life history variants (e.g., Beechie et al. 2006b; Fig. 1C). Large dams have excluded thousands of miles of habitat with a single barrier, and thousands of small dams and culverts have blocked a few miles of habitat each, resulting in massive cumulative losses of habitat area and habitat diversity. These habitat effects translate into decreased salmon abundance and decreased life history diversity. In coming decades a large number of dams in the Pacific Northwest will be reviewed for environmental compliance, and in many cases it might be more cost effective to remove the dams than retrofit them for continued use. This will provide an opportunity to restore many miles of river to something approaching historical conditions and help restore disturbance regimes that fall within the historical template.

Humans have a long history of trying to engineer solutions to environmental problems (e.g., Meffe 1992), and the allure of this approach remains tempting to many (e.g., Brannon 2006). Just as hatcheries have been used for over a century to 
Fig. 1. Examples of three types of restoration actions that can increase resilience to climate change. (A) Levee setbacks release a constraint on river channel migration and allow formation of multiple habitat types across a river floodplain, based in part on Pess et al. (2005b). (B) Use of stormwater-detention basins can help attenuate exaggerated flood regimes caused by urban development and might reduce peak flows below critical mortality thresholds, based in part on Booth et al. (2002). (C) Restoration of migration pathways to historically accessible habitats can increase both habitat and life history diversity (modified from Beechie et al. 2006b).

A. Relax constraints on habitat diversity: floodplain habitats
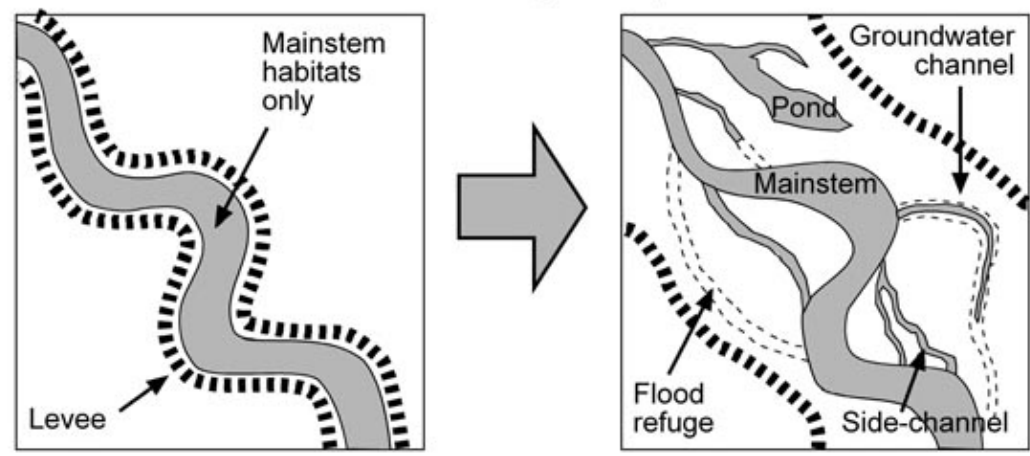

B. Attenuate exaggerated disturbance regimes: environmental flow restoration
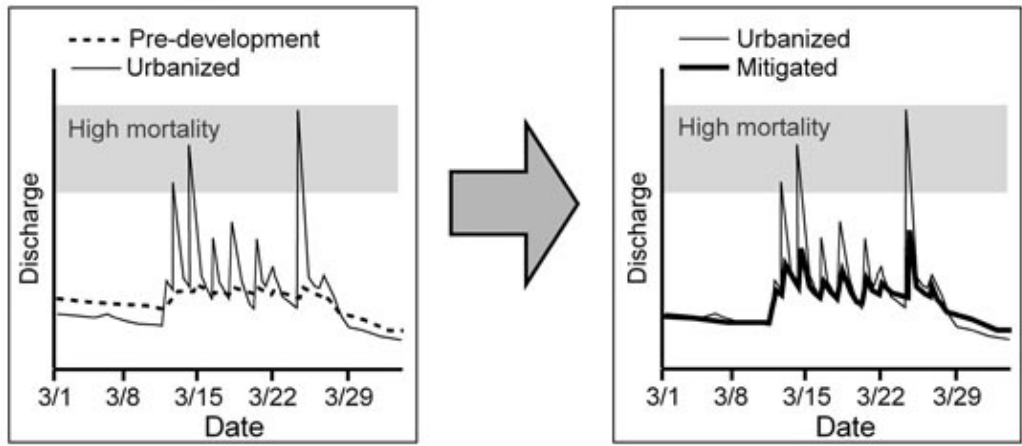

C. Restore migration pathways to diverse habitats: dam removal or fish passage

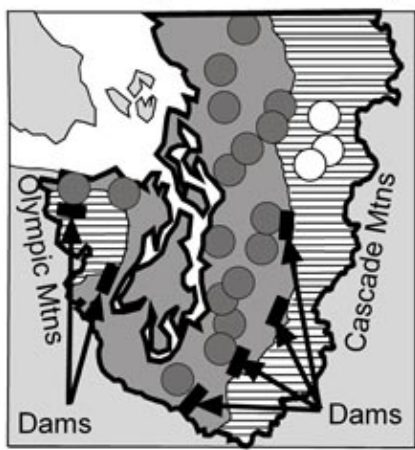

Rainfall/transitional hydrologic regime

Ocean-type Chinook population

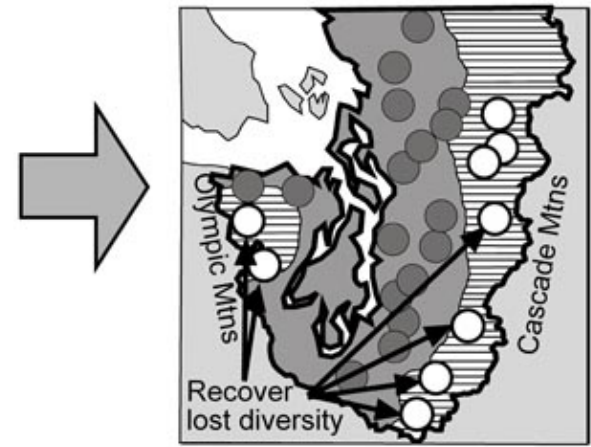

Snowmelt hydrologic regime Stream-type Chinook population 
compensate for losses of salmon populations, artificially created habitats frequently have been used as mitigation for lost or degraded habitats and ecosystem functions. The parallel extends further: hatcheries have been largely unsuccessful in accomplishing their stated goals (Lichatowich 1999), and engineered habitats seldom have replaced the full range of conditions that have been lost (National Research Council 1996, Bisson et al. 1997) and rarely if ever have mitigated fully losses to fisheries (Hilborn and Winton 1993, Roni et al. 2002). These results argue for the importance of conserving natural processes to promote health and resilience of both physical and biological systems.

Ironically, restoration of pristine habitat conditions could produce a bumpy ride for some salmon populations, at least in the short term. This could occur, for example, if the population has become adapted to altered environmental conditions. Williams et al. (2008) discussed how this might be the case with fall-run Chinook salmon in the Snake River, which are listed as a threatened species under the U.S. Endangered Species Act. This population spawns and rears in the mainstem Snake River; historically, juveniles virtually all migrated to sea in their first summer, as subyearling smolts. According to a model that has been proposed to explain expression of salmon life history traits (Thorpe et al. 1998), this historical pattern indicated that essentially the entire population of juveniles grew fast enough to reach the threshold for subyearlings molting. Evolution toward fast growth rates might have been spurred by a lack of suitable overwintering habitat in the river, which would select against slower-growing fish. Following extensive hydropower development, the ColumbiaSnake River system has been turned into a series of slack-water reservoirs that provide favorable winter habitat for salmonids. Empirical data show that an increasing fraction of the population now delays smolt migration until the following spring, and these yearling smolts have much higher survival to adult than subyearlings. Thus, it appears that current conditions selectively favor a shift away from the historic life history traits in this population. What will happen if the dams are ever removed, as some propose? If the recent, observed shift toward the yearling strategy primarily reflects phenotypic plasticity, one might expect the population to show a demographic rebound as mortality associated with dam passage is reduced. However, if the shift in life history reflects genetic change in the population, $i$. e., adaptation to current, altered conditions, then the population might find itself temporarily ill-adapted to take advantage of the restored habitat conditions.

How close to the historical template do the attributes of disturbance regimes need to be to promote resilience? At present our knowledge of salmon biology is not sufficient to answer that question with certainty. Empirical data show that salmon can deal to some extent with changing environmental conditions through phenotypic plasticity, and contemporary microevolution of salmon life histories has been documented over human lifetimes (Quinn et al. 2001, Hendry and Stearns 2004). However, we have only a very imperfect understanding of the limits of these processes in specific situations. This is an active area of research, particularly with respect to the response of salmon to future climate changes, and we expect that important new insights will be developed within the next 5-10 yr. In the meantime, a precautionary approach would suggest that restoration efforts should attempt to shape habitat processes in ways that promote disturbance regimes as close as possible to the historical template.

Responses to this article can be read online at:

http://www.ecologyandsociety.org/voll4/iss1/art3/responses/

\section{Acknowledgments:}

We thank Rick Gustafson, Jeff Hard, Orlay Johnson, Jim Myers, and Laurie Weitkamp for providing information for Table 2, and Jack Williams and an anonymous reviewer for thoughtful comments on an earlier draft.

\section{LITERATURE CITED}

Beechie, T. J., and S. Bolton. 1999. An approach to restoring salmonid habitat-forming processes in Pacific Northwest watersheds. Fisheries $\mathbf{2 4}$ (4):6-15.

Beechie T. J., B. D. Collins, and G. R. Pess. 2001. Holocene and recent geomorphic processes, land use and salmonid habitat in two north Puget Sound river basins. Pages 37-54 in J. B. Dorava, D. R. Montgomery, F. Fitzpatrick, and B. Palcsak, editors. Water Science and Application Volume 4: 
Geomorphic processes and riverine habitat. American Geophysical Union, Washington, D.C., USA.

Beechie, T. J., M. Liermann, M. M. Pollock, S. Baker, and J. Davies. 2006a. Channel pattern and river-floodplain dynamics in forested mountain river systems. Geomorphology 78(1-2):124-141.

Beechie, T. J, G. Pess, P. Kennard, R. E. Bilby, and S. Bolton. 2000. Modeling recovery rates and pathways for woody debris recruitment in northwestern Washington streams. North American Journal of Fishery Management 20:436-452.

Beechie, T., E. Buhle, M. Ruckelshaus, A. Fullerton, and L. Holsinger. 2006b. Hydrologic regime and the conservation of salmon life history diversity. Biological Conservation 130:560-572. ERRATUM

Beechie, T. J., E. A. Steel, P. R. Roni, and E. Quimby, editors. 2003. Ecosystem recovery planning for listed salmon: an integrated assessment approach for salmon habitat. NOAA Technical Memorandum NMFS-NWFSC-58, National Marine Fisheries Service, Seattle, Washington, USA.

Benda, L., and T. Dunne. 1997. Stochastic forcing of sediment supply to channel networks from landsliding and debris flow. Water Resources Research 33:2865-2880.

Beschta, R. L., M. R. Pyles, A. E. Skaugset, and C. G. Surfleet. 2000. Peakflow response to forest practices in the western Cascades of Oregon, USA. Journal of Hydrology 233:102-120.

Bisson, P. A., G. H. Reeves, R. E. Bilby, and R. J. Naiman. 1997. Watershed management and Pacific salmon: desired future conditions. Pages 447-474 in D. J. Stouder, P. A. Bisson, and R. J. Naiman, editors. Pacific salmon and their ecosystems: status and future options. Chapman and Hall, New York, New York, USA.

Bisson, P., J. Dunham, and G. Reeves. 2009. Freshwater ecosystems and resilience of Pacific salmon: habitat management based on natural variability. Ecology and Society 14, In press.

Booth, D. B., D. Hartley, and R. Jackson. 2002. Forest cover, impervious-surface area and the mitigation of stormwater impacts. Journal of the American Water Resources Association 38:835-845.

Bottom, D. L, C. A. Simenstad, J. Burke, A. M. Baptista, D. A. Jay, K. K. Jones, E. Casillas, and M.H.Schiewe. 2005. Salmon at river's end: the role of the estuary in the decline and recovery of Columbia River salmon. United States Department of Commerce, NOAA Technical Memo NMFSNWFSC-68. Available online at: http://www.nwfsc. noaa.gov/publications/displayallinfo.cfm? docmetadataid $=6294$

Bottom, D. L., K. K. Jones, C. A. Simenstad, and C. L. Smith. 2009. Reconnecting social and ecological resilience in salmon ecosystems. Ecology and Society 14(1): 5. [online] URL: http:// www.ecologyandsociety.org/vol14/iss1/art5/.

Brannon, E. L. 2006. Engineering the future for wild salmon and steelhead. Pages 175-192 in Lackey, R. T., D. H. Lach, and S. L. Duncan, editors. Salmon 2100: the future of wild Pacific salmon. American Fisheries Society, Bethesda, Maryland, USA.

Brenkman, S. J., and S. C. Corbett. 2005. Extent of anadromy in bull trout and implications for conservation of a threatened species. North American Journal of Fisheries Management 25:1073-1081.

Burgner, R. L. 1991. Life history of Sockeye salmon Oncorhynchus nerka. Pages 3-117 in C. Groot and L. Margolis, editors, Pacific salmon life histories. University of British Columbia Press, Vancouver, British Columbia, Canada.

Collins, B. D., and D. R. Montgomery. 2001. Importance of archival and process studies to characterizing pre-settlement riverine geomorphic processes and habitat in the Puget Lowland. Pages 227-243 in J. B. Dorava, D. R. Montgomery, F. Fitzpatrick, and B. Palcsak, editors. Geomorphic processes and riverine habitat, Water Science and Application Volume 4, American Geophysical Union, Washington, D.C., USA.

Collins, B. D., D. R. Montgomery, and A. D. Haas. 2002. Historical changes in the distribution and functions of large wood in Puget Lowland rivers. Canadian Journal of Fisheries and Aquatic Sciences 59:66-76. 
Dauble, D. D., and D. R. Geist. 2000. Comparison of mainstem spawning habitats for two populations of fall Chinook salmon in the Columbia River basin. Regulated Rivers: Research and Management 16:345-361.

Evenden, M. 2004. Social and environmental change at Hells Gate, British Columbia. Journal of Historical Geography 30:130-153.

Foerster, R. E. 1947. Experiment to develop sea run from land locked Sockeye salmon (Oncorhynchus nerka kennerlyi). Journal of the Fisheries Research Board of Canada 7:88-93.

Foerster, R. E. 1968. The sockeye salmon, Oncorhynchus nerka. Bulletin of the Fisheries Research Board of Canada 162.

Good, T. P., J. R. Davies, B. J. Burke, and M. H. Ruckelshaus. 2008. Incorporating catastrophic risk assessments into setting conservation goals for Pacific salmon. Ecological Applications 18 (1):246-257.

Available online at: http://www.nwfsc.noaa.gov/pu blications/displayallinfo.cfm?docmetadataid $=6609$

Greene, C. M., D. Jensen, G. R. Pess, E. M. Beamer, and E. A. Steel. 2005. Effects of environmental conditions during stream, estuary, and ocean residency on Chinook salmon return rates in the Skagit River, WA. Transactions of the American Fisheries Society 134:1562-1581.

Groot, C., and I. Margolis. 1991. Pacific salmon life histories. University of British Columbia Press, Vancouver, British Columbia, Canada.

Gustafson, R. G., and G. A. Winans. 1999. Distribution and population genetic structure of river-and sea-type sockeye salmon in western North America. Ecology of Freshwater Fish 8:181-193.

Healey, M. C. 2009. Resilient salmon, resilient fisheries for British Columbia, Canada. Ecology and Society 14(1): 2. [online] URL: http://www.ecology andsociety.org/vol14/iss1/art2/

Hendry, A. P, and S. C. Stearns, editors. 2004. Evolution illuminated: salmon and their relatives. Oxford University Press, Oxford, UK.

Hilborn, R., and J. Winton. 1993. Learning to enhance salmon production: lessons from the Salmonid Enhancement Program. Canadian Journal of Fisheries and Aquatic Sciences 50:2043-2056.

Hilborn R, T. P. Quinn, D. E. Schindler, and D. E. Rogers. 2003. Biocomplexity and fisheries sustainability. Proceedings of the National Academy of Sciences, USA. 100(11):6564-6568. Available online at: http://www.pnas.org/content/1 00/11/6564.full.pdf.

Holling, C. S. 1973. Resilience and stability of ecological systems. Annual Review of Ecology and Systematics 4:1-23.

Hutchings, J. A. 2004. Norms of reaction and phenotypic plasticity in salmonid life histories. Pages 154-174 in A. Hendry and S. Stearns, editors. Evolution illuminated: salmon and their relatives. Oxford University Press, Oxford, UK.

Independent Scientific Group. 1999. Scientific issues in the restoration of salmonid fishes in the Columbia River. Fisheries 24:10-19.

Kaeriyama, M., S. Urawa, and T. Suzuki. 1992. Anadromous sockeye salmon (Oncorhynchus nerka) derived from nonanadromous kokanees: life history in Lake Toro. Scientific Reports of the Hokkaido salmon Hatchery 46:157 174.

Kinsella, W. P. 1982. Shoeless Joe. Houghton Mifflin, New York, New York, USA.

Koski, K V. 2009. The fate of coho salmon nomads: the story of an estuarine rearing strategy promoting resilience. Ecology and Society 14(1): 4. [online] URL: http://www.ecologyandsociety.org/vol14/iss1/ $\underline{\operatorname{art} 4 /}$

Lackey, R. T., D. H. Lach, and S. L. Duncan, editors. 2006. salmon 2100: the future of wild Pacific salmon. American Fisheries Society, Bethesda, Maryland, USA.

Latterell J. J., J. S. Bechtold, T. C. O'Keefe, R. Van Pelt, and R. J. Naiman. 2007. Dynamic patch mosaics and channel movement in an unconfined river valley of the Olympic Mountains. Freshwater Biology 52 (1):523-544.

Leider. S. A. 1989. Increased straying by adult steelhead trout (Salmo gairdneri) following the 
1980 eruption of Mount St. Helens. Environmental Biology of Fishes 24:219-229.

Lichatowich, J. A. 1999. Salmon without rivers: a history of the Pacific salmon crisis. Island Press, Washington, D.C., USA.

Lytle, D. A., and L. Poff. 2004. Adaptation to natural flow regimes. Trends in Ecology and Evolution 19:94-100.

McClure, M. M., S. M. Carlson, T. J. Beechie, G. R. Pess, J. C. Jorgensen, S. M. Sogard, S. E. Sultan, D. M. Holzer, J. Travis, B. L. Sanderson, M. E. Power, and R. W. Carmichael. 2008. Evolutionary consequences of habitat loss for Pacific anadromous salmonids. Evolutionary Applications 1:300-318.

McElhany, P., M. H. Ruckelshaus, M. J. Ford, T. C. Wainwright, and E.P. Bjorkstedt. 2000. Viable salmonid populations and the recovery of evolutionarily significant units. NOAA Technical Memorandum NMFS-NWFSC-42. National Marine Fisheries Service, NOAA, Seattle, Washington, USA.

McMillan, J., G. Pess, and S. Katz. 2007. Observational evidence of spatial and temporal structure in a sympatric anadromous (winter steelhead) and resident rainbow trout mating system on the Olympic Peninsula, Washington. Transactions of the American Fisheries Society 136:736-748.

Meffe, G. K. 1992. Techno-arrogance and halfway technologies: salmon hatcheries on the Pacific coast of North America. Conservation Biology 6:350-354.

Milner, A. M., and R. G. Bailey. 1989. salmonid colonization of new streams in Glacier Bay National Park, Alaska. Aquaculture and Fisheries Management 20:179-192.

Moritz, C. 2002. Strategies to protect biological diversity and the evolutionary processes that sustain it. Systematic Biology 51:238-254.

National Research Council. 1996. Upstream: salmon and society in the Pacific Northwest. National Academy Press, Washington, D.C., USA.

O'Connor, J. E. 2004. The evolving landscape of the Columbia River Gorge: Lewis and Clark and cataclysms on the Columbia. Oregon Historical Quarterly 105:390-420.

Pavey, S.A., T. R. Hamon, and J. L. Nielsen. 2007. Revisiting evolutionary dead ends in sockeye salmon (Oncorhynchus nerka) life history. Canadian Journal of Fisheries and Aquatic Sciences 64:1199-1208.

Pess, G. R., S. A. Morley, J. L. Hall, and R. K. Timm. 2005a. Monitoring floodplain restoration. Pages 127-166 in Roni, P., editor. Methods for monitoring stream and watershed restoration. American Fisheries Society, Bethesda, Maryland, USA.

Pess, G. R., S. A. Morley, and P. Roni. $2005 b$. Evaluating fish response to culvert replacement and other methods for reconnecting isolated aquatic habitats. Pages 267-276 in P. Roni, editor. Methods for monitoring stream and watershed restoration. American Fisheries Society, Bethesda, Maryland, USA.

Poff, N. L., J. D. Olden, M. D. Merritt, and D. M. Pepin. 2007. Homogenization of regional river dynamics by dams and global biodiversity implications. Proceedings of the National Academy of Sciences, USA. 104:5732-5737.

Pollock, M. M., T. J. Beechie, and C. E. Jordan. 2007. Geomorphic changes upstream of beaver dams in Bridge Creek, an incised stream channel in the interior Columbia River basin, eastern Oregon. Earth Surface Processes and Landforms 32:1174-1185.

Quinn, T. P. 2005. The behavior and ecology of Pacific salmon and trout. University of Washington Press, Seattle, Washington, USA.

Quinn, T. P., M. T. Kinnison, and M. J. Unwin. 2001. Evolution of Chinook salmon (Oncorhynchus tshawytscha) populations in New Zealand: pattern, rate and process. Genetica 112-113:493-513.

Reeves, G. H., L. E. Benda, K. M. Burnett, P. A. Bisson, and J. R. Sedell. 1995. A disturbance-based ecosystem approach to maintaining and restoring freshwater habitats of evolutionarily significant units of anadromous salmonids in the Pacific Northwest. American Fisheries Society Symposium 17:334-349.

Richter, B. D., A. T. Warner, J. L. Meyer, and K. 
Lutz. 2006. A collaborative and adaptive process for developing environmental flow recommendations. River Research and Applications 22:297-318.

Riva-Rossi, C., M. A. Pascual, J. A., Babaluk. M. Garcia, and N. M. Haldman. 2007. Intrapopulation variation in anadromy and reproductive life in rainbow trout introduced in the Santa Cruz River, Argentina. Journal of Fish Biology 70:1780-1797.

Roghair, C. N., and C. A. Dolloff. 2005. Brook trout movement during and after recolonization of a naturally defaunated stream reach. North American Journal of Fish Management 22:777-784.

Roni, P., T. J. Beechie, R. E. Bilby, F. E. Leonetti, M. M. Pollock, and G. R. Pess. 2002. A review of stream restoration techniques and a hierarchical strategy for prioritizing restoration in Pacific Northwest watersheds. North American Journal of Fisheries Management 22:1-20.

Sheer, M. B., and E. A. Steel. 2006. Lost watersheds: barriers, aquatic habitat connectivity, and species persistence in the Willamette and Lower Columbia basins. Transactions of the American Fisheries Society 135:1654-1669.

Stanford, J. A., J. V. Ward, W. J. Liss, C. A. Frissell, R. N. Williams, J. A. Lichatowich, and C. C. Coutant. 1996. A general protocol for restoration of regulated rivers. Regulated Rivers 12:391-413.

Sumioka, S. S., D. L. Kresch, and K. D. Kasnick. 1998. Magnitude and frequency of floods in Washington. USGS Water Resources Investigations Report 97-4277, Tacoma, Washington, USA.

Taylor, E. B. 1991. A review of local adaptation in salmonidae, with particular reference to Pacific and Atlantic salmon. Aquaculture 98:185-207.

Thériault, V., E. S. Dunlop, U. Dieckmann, L. Bernatchez, and J. J. Dodson. 2008. The impact of fishing-induced mortality on the evolution of alternative life-history tactics in Brook Charr. Evolutionary Applications 1:409-423.

Thorpe, J. E., M. Mangel, N. B. Metcalfe, and F. A. Huntingford. 1998. Modelling the proximate basis of salmonid life history variation, with application to Atlantic salmon, Salmo salar L. Evolutionary Ecology 12:581-599.
Waples, R. S. 1991. Pacific salmon, Oncorhynchus spp. and the definition of "species" under the Endangered Species Act. Marine Fisheries Review 53(3):11-22.

Waples, R.S. 1995. Evolutionarily significant units and the conservation of biological diversity under the Endangered Species Act. American Fisheries Society Symposium 17:8-27.

Waples, R. S., R. G. Gustafson, L. A. Weitkamp, J. M. Myers, O. W. Johnson, P. J. Busby, J. J. Hard, G. J. Bryant, F. W. Waknitz, K. Neely, D. Teel, W. S. Grant, G. A. Winans, S. Phelps, A. Marshall, and B. Baker. 2001. Characterizing diversity in Pacific salmon. Journal of Fish Biology 59(A):1-41.

Waples, R. S., D. J. Teel, J. Myers, and A. Marshall. 2004. Life history divergence in Chinook salmon: historic contingency and parallel evolution. Evolution 58:386-403.

Waples, R. S., G. R. Pess, and T. Beechie. 2008. Evolutionary history of Pacific salmon in dynamic environments. Evolutionary Applications 1:189-206.

Ward, J. V., and J. A. Stanford. 1995. Ecological connectivity in alluvial river ecosystems and its disruption by flow regulation. Regulated Rivers: research and management 11:105-119.

Williams, R. N. 2006. Return to the river: restoring salmon to the Columbia River. Elsevier Academic Press, London, UK.

Williams, J. G., R. W. Zabel, R. S. Waples. J. A. Hutchings, and W. P. Connor. 2008. Potential for anthropogenic disturbances to influence evolutionary change in the life history of a threatened salmonid. Evolutionary Applications 1:271-285.

Wood, C. C. 1995. Life history variation and population structure in sockeye salmon. American Fisheries Society Symposium 17:195-216.

Wood, C. C. 2007. Sockeye salmon ecotypes: origin, vulnerability to human impacts, and conservation value. American Fisheries Society Symposium 54:1-4.

Wood, C. C., J. W. Bickham, R. J. Nelson, C. J. Foote, and J. C. Patton. 2008. Recurrent evolution 
of life history ecotypes in sockeye salmon: implications for conservation and future evolution. Evolutionary Applications 1:207-221. 